\title{
Sulforaphane prevents PC12 cells from oxidative damage via the Nrf2 pathway
}

\author{
BING BAO, MAN-QING ZHANG, ZHI-YING CHEN, XIANG-BING WU, \\ ZHONG-BING XIA, JING-YAN CHAI and XIAO-PING YIN
}

\begin{abstract}
Department of Neurology, The Affiliated Hospital of Jiujiang College, Jiujiang, Jiangxi 33200, P.R. China
\end{abstract}
Received December 7, 2018; Accepted April 3, 2019

DOI: $10.3892 / \mathrm{mmr} .2019 .10148$

\begin{abstract}
The aim of this study was to investigate the protective effect of sulforaphane (SFN) on 1-methyl-4-phenyl pyridine ion (MPP+)-induced cytotoxicity and to investigate its possible mechanisms. Methods: PC12 cell toxicity induced by MPP+ served as a cell model of Parkinson's diseases. The cell culture + experiments were divided into four groups based on the different treatments, namely, vehicle control, SFN, $\mathrm{MPP}+$ and SFN pretreatment plus MPP+. Cell viability and apoptosis were examined by MTT assay and flow cytometry, respectively. Expressions of nuclear factor erythroid 2-related factor 2 (Nrf2), heme oxygenase 1 (HO-1) and nicotinamide quinone oxidoreductase 1 (NQO1) were detected using western blotting. Results: MPP+ reduced the survival rate of PC12 cells in a dose- and time-dependent manner. After 24-h treatment with $500 \mu \mathrm{mol} / 1 \mathrm{MPP}+$, the survival rate of PC12 cells decreased to $58.2 \pm 0.03 \%$ of that in the control groups. Under the same conditions MPP+ resulted in significant apoptosis of PC12 cells (apoptosis rate: $30.4 \pm 0.6 \%$ ). However, SFN pretreatment significantly attenuated the cell damage induced by MPP+. Furthermore, it was demonstrated that SFN reversed the reduction of Nrf2, HO-1 and NQO1 expression induced by MPP+. Conclusion: SFN may protect PC12 cells from MPP+-induced damage via activating the Nrf2-ARE (antioxidant responsive element) pathway.
\end{abstract}

\section{Introduction}

Parkinson's disease (PD) is a long-term degenerative disorder of the central nervous system. It is characterized by a progressive loss of dopaminergic neurons in the substantia nigra. PD affects $\sim 6$ million people worldwide and its prevalence is $1 \%$

Correspondence to: Dr Xiao-Ping Yin, Department of Neurology, The Affiliated Hospital of Jiujiang College, 57 East Xunyang Road, Jiujiang, Jiangxi 33200, P.R. China

E-mail: xiaopingbuxiao@126.com

Key words: sulforaphane, PC12 cells, nuclear factor erythroid 2-related factor 2, 1-methyl-4-phenyl pyridine ion, oxidative stress, Parkinson's disease in the population aged 60 or over (1). To date, studies demonstrated that PD may involve oxidative stress, mitochondrial dysfunction, lysosomal dysfunction and neuroinflammatory changes $(1,2)$. Among them, oxidative stress serves a pivotal role in PD development (3-5). Neurotoxin-based models of PD (particularly, 1-methyl-4-phenyl-1,2,3,6-tetrahydropyridine; MPTP) are important in elucidating the molecular cascade of cell death in dopaminergic neurons (1). MPTP itself is not toxic, but its oxidized product, 1-methyl-4-phenyl pyridine ion (MPP+), is harmful. MPP+ interferes with oxidative phosphorylation in mitochondria by inhibiting complex I of the electron transport chain, resulting in the depletion of ATP and excessive formation of reactive oxygen species (ROS), ultimately leading to cell death (6). PC12 cells originate from a rat pheochromocytoma and exhibit the properties of neurosecretory cells and dopaminergic neurons (7). PC12 cells are commonly used for PD studies $(8,9)$. In this study, $\mathrm{PC} 12$ cell damage induced by $\mathrm{MPP}+$ served as a cell model of PD.

At present, PD treatments are symptomatic and no medication is available to reverse or prevent its progression. This has led to the search for a novel pharmacological and neuroprotective treatment. SFN, a natural phytochemical and a second enzyme inducer, has previously drawn increasing attention due to its beneficial effects on a number of medical conditions (10). Studies demonstrated that SFN has multiple anti-pathological actions including antitumor $(11,12)$, antioxidant (13), immune regulation (14) and anti-inflammatory effects (15). A number of mechanisms and signal pathways are associated with the biological effects of SFN. Among them, Nrf2 is one of the critical signal molecules $(16,17)$. As an important transcription factor, Nrf2 targets genes called antioxidant response element, which encodes several antioxidant enzymes including (HO-1) and nicotinamide quinone oxidoreductase 1 (NQO1). These enzymes are key players in the redox balance of cells and provide cytoprotection against prooxidant stimuli (18-22). In the present study, whether SFN protects $\mathrm{PC} 12$ cells against the toxicity of MPP+ was investigated and the possible mechanism was explored. The present study may provide evidence that SFN could be a potential compound to prevent PD progression.

\section{Materials and methods}

Cell culture. PC12 cells (undifferentiated) were purchased from the Shanghai Cell Bank of Chinese Academy of Sciences and 
were cultured in DMEM high glucose medium (Hyclone, GE Healthcare) supplemented with $10 \%$ fetal bovine serum (Gibco; Thermo Fisher Scientific, Inc.), 1\% penicillin-streptomycin mixture and $4 \mathrm{mmol} / \mathrm{l} \mathrm{L-glutamine}$. The culture was placed in a humidified incubator with $5 \% \mathrm{CO}_{2}$ and $95 \%$ air at $37^{\circ} \mathrm{C}$. The cells were subcultured every 3 days and cells at a logarithmic growth phase were used for the experiments.

MTT colorimetric assay. The density of PC12 cells was adjusted to $5 \times 10^{5}$ cells $/ \mathrm{ml}$ and the cells (100 $\left.\mu \mathrm{l} / \mathrm{well}\right)$ were seeded on a 96 -well microplate. Following a total of $24 \mathrm{~h}$ of growth in a humidified incubator, the different compounds were added into the cultures. A total of 5 parallel wells were used for a specific treatment and the experiments were independently repeated three times. For the MPP+ group, the cells were treated with serial concentrations of MPP+ $(100,300,500$ and $700 \mu \mathrm{mol} / \mathrm{l})$ and incubated for different periods of time (12, 24 and $48 \mathrm{~h})(23)$. For the SFN group, the cells were incubated with SFN $(0.5,1.0,2.5,5.0$ and $10 \mu \mathrm{mol} / 1)$ for $24 \mathrm{~h}$. For the SFN plus MPP+ group, the cells were pretreated with different concentrations of SFN $(0.5,1.0,2.5,5.0$ and $10 \mu \mathrm{mol} / \mathrm{l})$ for $1 \mathrm{~h}$, then MPP+ $(500 \mu \mathrm{mol} / \mathrm{l})$ was added and the cultures were continued for $24 \mathrm{~h}$. Following the different treatments, cell viability was determined by MTT colorimetric assay as described previously (24). Briefly, $20 \mu \mathrm{l}$ of MTT solution $(5 \mathrm{mg} / \mathrm{ml})$ was added into each well and incubated with the cells for $4 \mathrm{~h}$ at $37^{\circ} \mathrm{C}$. Subsequently the medium was carefully replaced with $150 \mu \mathrm{l}$ DMSO and a 10 min oscillation was applied to sufficiently dissolve the crystal. The absorbance value at $570 \mathrm{~nm}$ was measured with a microplate reader. The cell survival rate was calculated as the ratio of absorbance of the experimental groups to that of the control group.

Flow cytometry analyses. Flow cytometry analyses were performed as described previously (25). In short, following the different treatments, PC12 cells were harvested and re-suspended in a $500 \mu 1$ binding buffer. The cells were labeled with $5 \mu$ l Annexin V-FITC (Nanjing KeyGen Biotech. Co. Ltd.) and $5 \mu \mathrm{l}$ of propidium iodide for $10 \mathrm{~min}$ in the dark. The apoptotic index was determined using a flow cytometer (BD Biosciences). All data were acquired and analyzed with Cellquest version 5.1 software (BD Biosciences).

Western blotting. Protein expression was assessed by western blotting according to the authors' previous study (26). In brief, the cell pellets were lysed in a RIPA lysis buffer (cat. no. R0020; Beijing Solarbio Science \& Technology Co., Ltd.) supplemented with proteinase and phosphatase inhibitor (Sigma-Aldrich; Merck KGaA). After centrifugation at $16,000 \mathrm{xg}$ at $4^{\circ} \mathrm{C}$ for $15 \mathrm{~min}$, the supernatant was harvested and the protein was quantified using the bicinchoninic acid protein assay (Merck KGaA). Equal amounts of protein (30-40 $\mu \mathrm{g}$ per well) were loaded on $12 \%$ SDS-PAGE and transferred to polyvinylidene fluoride membranes (EMD Millipore). The membrane was blocked with a 5\% nonfat milk solution for $2 \mathrm{~h}$ at room temperature. Then the membrane was incubated with the primary antibodies overnight at $4^{\circ} \mathrm{C}$ (Santa Cruz Biotechnology, Inc.) against Nrf2 (1:100, sc-518036), HO-1 (1:100, sc-136960) and NQO1 (1:200, sc-376023), respectively. Following incubation with the secondary antibody $(1: 1,000$, goat anti-mouse IgG-HRP, sc-2005, Santa Cruz Biotechnology, Inc.) for $2 \mathrm{~h}$ at room temperature, the blot bands were detected with ECL substrate (Clarity Max ${ }^{\mathrm{TM}}$, Bio-Rad Laboratories, Inc.). $\beta$-actin (1:500, sc-47778, Santa Cruz Biotechnology, Inc) was used as an internal control. The western blot images were analyzed with ImageJ software (v1.52, National Institutes of Health), and protein levels were expressed as the ratio of values of the detected protein bands to that of $\beta$-actin bands.

Chemicals. SFN and MPP+ were purchased from SigmaAldrich and Merck KGaA.

Statistical analysis. The data are presented as the mean \pm standard error of mean and GraphPad Prism 7.0 (GraphPad Software, Inc.) was used to perform the statistical analysis. One-way or two-way analysis of variance was conducted to examine the differences among the multiple groups, followed by Turkey post-hoc analysis. $\mathrm{P}<0.05$ were considered to indicate a statistically significant difference.

\section{Results}

$M P P+$ reduces the survival rate of $\mathrm{PC} 12$ cells. In order to evaluate the toxic effects of MPP+ on PC12 cells, the cells were incubated with different concentrations of MPP+ and examined the cell viability at different time points. It was identified that MPP+ decreased the cell viability in a doseand time-dependent manner (Fig. 1). The results of the present study are in line with previous studies that MPP+ caused significant damage to PC12 cells $(27,28)$.

SFN protects against the cytotoxicity induced by $M P P+$. Next whether SFN could protect PC12 cells against the cytotoxicity of the MPP+ was examined. As presented in Figs. 2A and 3, SFN alone did not affect the viability or apoptosis of PC12 cells. However, SFN (1-10 $\mu \mathrm{mol} / 1)$ pretreatment significantly attenuated the toxic effects of MPP+ on PC12 cells in a dose-dependent fashion ( $\mathrm{P}<0.01$; Fig. $2 \mathrm{~B})$.

Consistent with the MTT experiments, flow cytometry data demonstrated that MPP+ significantly increased apoptosis of PC12 cells. After $24 \mathrm{~h}$ treatment, $500 \mu \mathrm{mol} / 1 \mathrm{MPP}+$ resulted in $30.4 \pm 0.6 \%$ apoptotic cells (Fig. 3). In addition, it was found that SFN significantly reduced the apoptosis of $\mathrm{PC} 12$ cells induced by $\mathrm{MPP}+(\mathrm{P}<0.01 ;$ Fig. 3$)$. At a concentration of $2.5 \mu \mathrm{mol} / 1$, SFN decreased the apoptosis rate induced by MPP+ from $30.4 \pm 0.6$ to $13.3 \pm 0.2 \%$ (Fig. 3 ). The results demonstrate that SFN can protect against MPP+ induced cytotoxicity.

SFN upregulates the Nrf2 signaling pathway. To investigate the signaling pathways involved in the protective effect of SFN, the expression of Nrf2, which is reported to be pivotal for the biological effects of SFN was examined (29). As presented in Fig. 4, MPP+ treatment significantly decreased Nrf2 expression in $\mathrm{PC} 12$ cells by western blotting $(\mathrm{P}<0.01)$. Although SFN itself did not alter the expression of Nrf2, SFN pretreatment $(2.5 \mu \mathrm{mol} / \mathrm{l})$ significantly reversed the reduced expression of $\mathrm{Nrf} 2$ caused by MPP+ treatment. Nrf2 is an important transcription factor and can regulate the expression of several antioxidant proteins including HO-1 and NQO1 (30). 


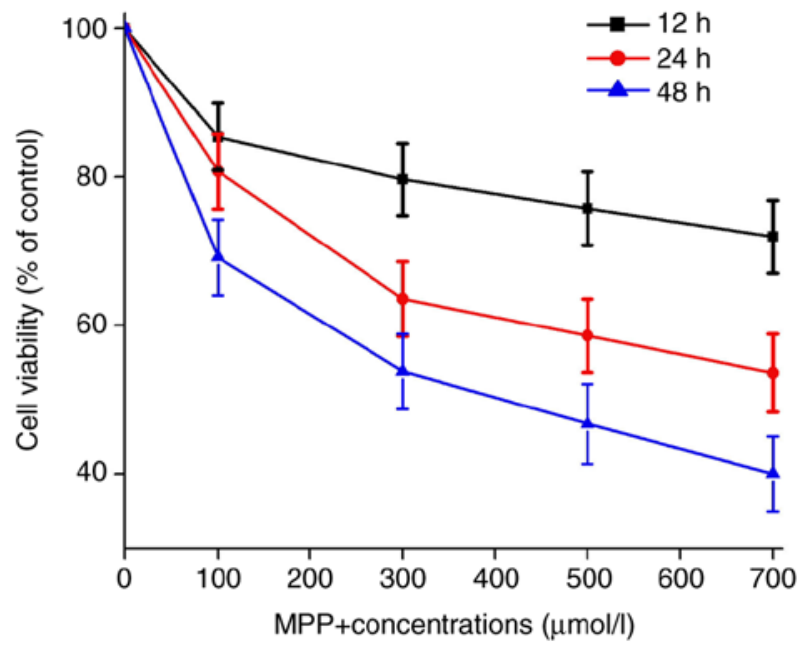

Figure 1. Effects of increasing concentrations of MPP+ on the viability of $\mathrm{PC} 12$ cells. MPP+, 1-methyl-4-phenyl pyridine ion.
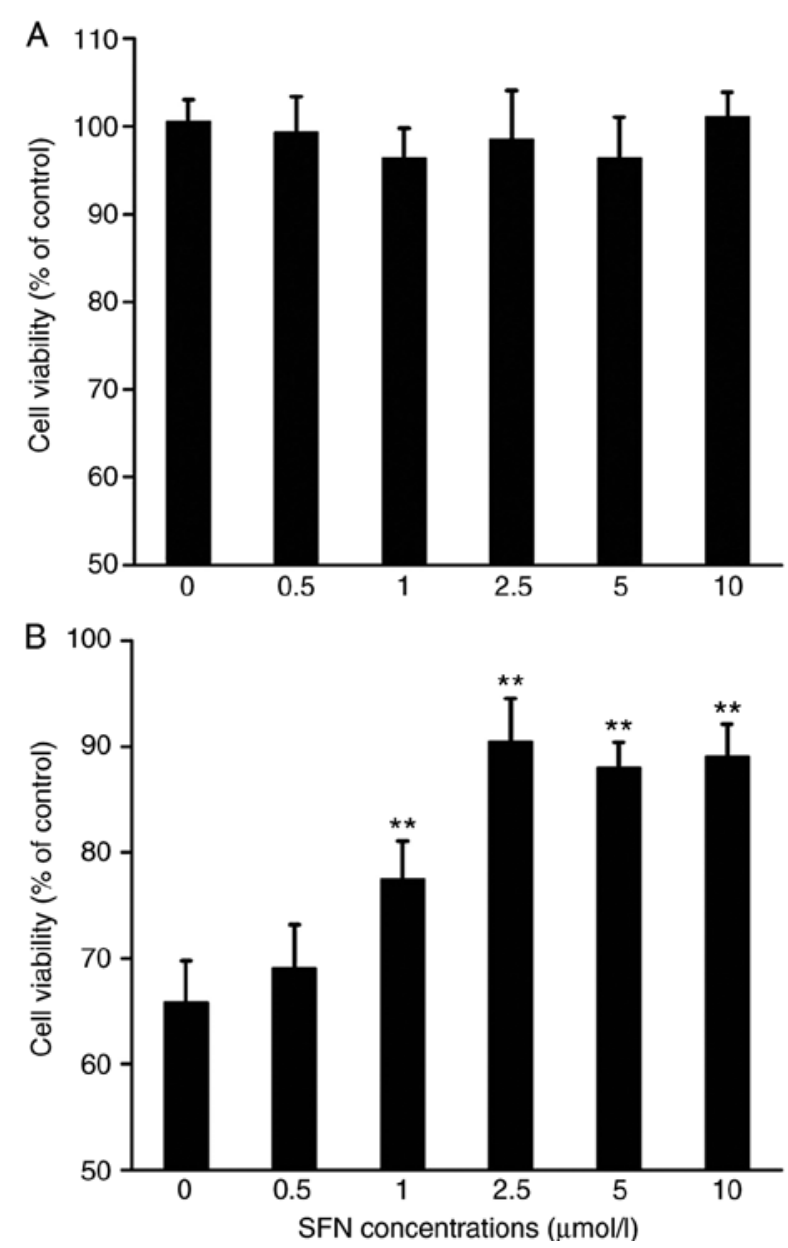

Figure 2. Effects of SFN or combination of SFN and MPP+ on the viability of PC12 cells. (A) Cell viability in the presence of increasing concentrations of SFN. (B) Cell viability with combination of $500 \mu \mathrm{mol} / 1 \mathrm{MPP}+$ and increasing concentration of SFN. ${ }^{* *} \mathrm{P}<0.01$ vs. $0 \mu \mathrm{mol} / 1 \mathrm{SFN}$. A one-way analysis of variance was used to analyze the data. SFN, sulforaphane; MPP+, 1-methyl-4-phenyl pyridine ion.

Therefore the expression of HO-1 and NQO1 was examined. Notably, the expression of HO-1 and NQO1 proteins exhibited a parallel change (Figs. 5 and 6), namely, MPP+ significantly reduced the expression of HO-1 and NQO1 $(\mathrm{P}<0.05)$, while $\mathrm{SFN}$ restores their expression. It is well documented that the Nrf2 signaling pathway serves an important role in neuron survival (30), the results of the present study suggest that SFN may attenuate the cell toxicity by sustaining the expression of Nrf2 and its downstream antioxidant enzymes.

\section{Discussion}

In the present study, using an MTT assay and flow cytometry, it was demonstrated that MPP+ dose-dependently caused damage to PC12 cells and SFN attenuated the detrimental effects of MPP+. Furthermore, it was identified that that the protective effects of SFN may act through restoring transcription factor Nrf2 signaling pathways.

Oxidative stress occurs due to an imbalance of free radical production and the antioxidant response system. The central nervous system is susceptible to oxidative stress because of its high rate of oxygen consumption and lipid-rich content (31). It is well established that oxidative stress is involved in a number neurodegenerative disorders including PD and Alzheimer disease (3). It has been long recognized that MPTP, a by-product of illegal heroin synthesis, can cause a parkinsonian syndrome among drug abusers (1). The nontoxic MPTP is converted to MPP+ by the enzyme of monoamine oxidase B. MPP+ accumulates in mitochondria and binds to complex I of the electron transport chain, leading to excessive production of ROS and therefore cell damage $(1,19,23,27,32)$. In the present study, it was demonstrated that MPP+ caused PC12 cell injury and apoptosis using an MTT assay and flow cytometry. The results agree with the previous studies (32-34). For example, Hartley et al (32) demonstrated that MPP+ caused cell apoptosis at low concentrations but necrosis at high concentrations. It is worth noting that treatment with $500 \mu \mathrm{mol} / 1 \mathrm{MPP}+$ for $24 \mathrm{~h}$ caused $\sim 42 \%$ cell death by MTT assay, while under the same condition an apoptotic rate of $\sim 30 \%$ was identified using flow cytometry. It seemed that there was a $12 \%$ difference in cell death between the two methods. Since the MTT assay can detect all kinds of cell death which include necrosis and apoptosis, the results of the present study suggest that the cell death induced by MPP+ was dominantly via apoptosis, but other mechanisms including necrosis may also contribute to cell death.

Notably, SFN was identified to dose-dependently prevent the cell damage induced by MPP+, although SFN itself did not affect the viability of PC12 cells. However, several studies demonstrated that SFN alone can induce apoptosis of breast and lung cancer cells (35-37), indicating that SFN may affect cell viability depending upon the cell types. SFN, an organosulfur compound derived from cruciferous vegetables, has recently gained attention for its multiple biological functions. Studies have demonstrated that SFN may be beneficial to a wide variety of diseases, including neurological degenerative disease $(38,39)$, cancer (40-42), heart disease (43), obesity (44) and asthma (45). SFN efficacy occurs by activating signaling molecules including Nrf2 (16,17,46-49), uncoupling protein-1 (44) and programmed cell death 4 (50). Among all the SFN associated signaling pathways, Nrf2 is well-established and is identified to be associated 
A
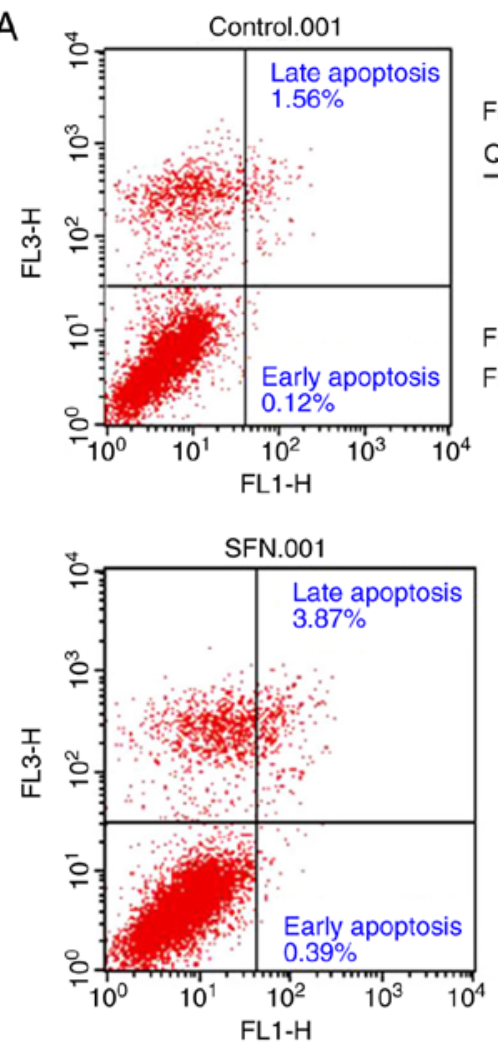

File: Control.001

Quad \% Gated

$\begin{array}{lr}\text { UL } & 11.02 \\ \text { UR } & 1.56\end{array}$

LL $\quad 87.30$

LR $\quad 0.12$

FL1: annexin V

FL3: PI

File: SFN.001

Quad \% Gated

UL 10.84

UR $\quad 3.81$

LL $\quad 84.96$

LR $\quad 0.39$

FL1: annexin V

FL3: PI

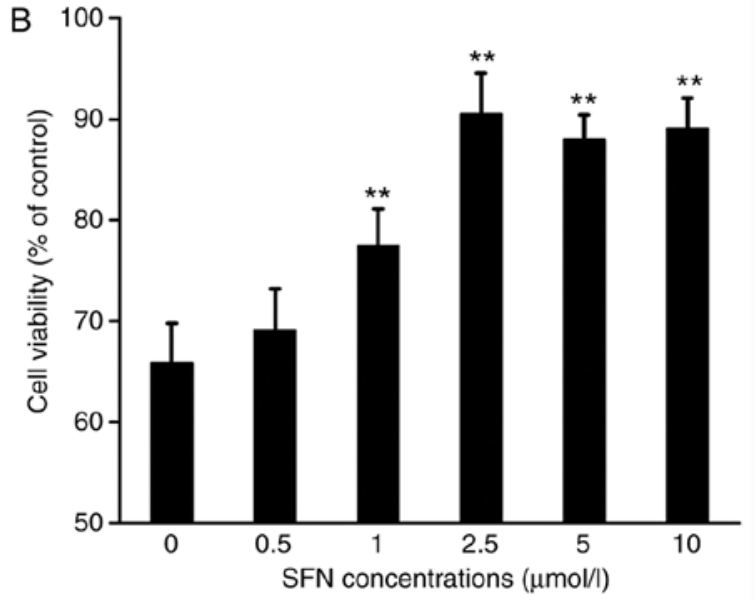

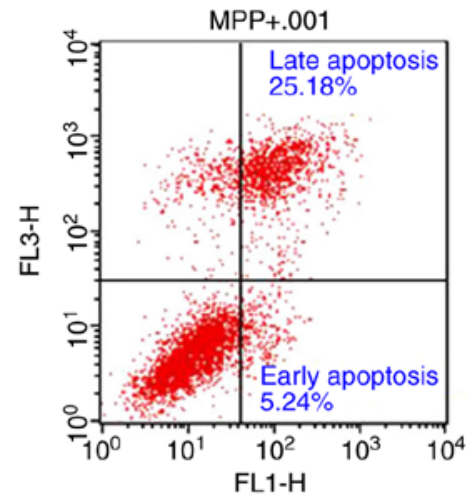

File: MPP +.001

Quad \% Gated

$\begin{array}{ll}\text { UL } & 6.92\end{array}$

UR $\quad 25.18$

LL $\quad 62.66$

LR $\quad 5.24$

FL1: annexin V

FL3: PI

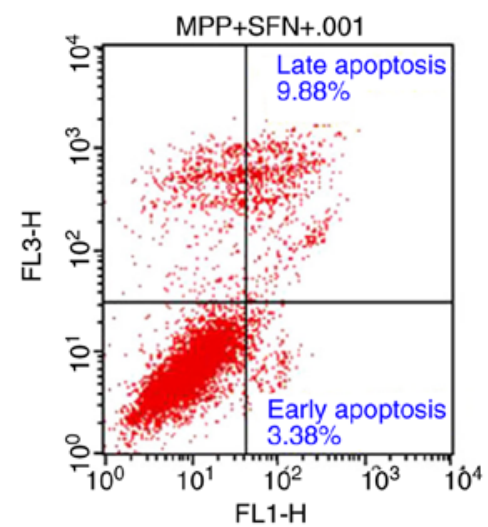

File: $\mathrm{MPP}+\mathrm{SFN}+.001$

Quad \% Gated

UL 8.22

UR 9.88

LL $\quad 78.51$

LR $\quad 3.38$

FL1: annexin V

FL3: PI

Figure 3. Apoptosis rate of PC12 cells is determined by flow cytometry using the annexin V-FITC/PI apoptosis assay following different treatments. (A) Representative scatter plots demonstrating apoptosis by Annexin V-FITC and PI staining and flow cytometry. UL, dead cells; UR, late apoptotic cells; LL, viable cells; LR, early apoptotic cells. (B) Summary data for apoptosis rate of PC12 cells treated with SFN, MPP+, or SFN and MPP+ together. ${ }^{* *} \mathrm{P}<0.01$ vs. the control group. One-way analysis of variance was used to analyze the data. SFN, sulforaphane; MPP+, 1-methyl-4-phenyl pyridine ion; PI, propidium iodide; FITC, fluorescein isothiocyanate.

with the protective effects of SFN on various diseases $(16,17)$. The Nrf2-antioxidant response element (ARE) pathway serves a critical role in the regulation of the oxidative stress response in a number of cell types (51). When Nrf2 is activated, it enters the nucleus and binds to a specific site, ARE, to activate an array of the phase II enzymes and antioxidant enzymes including HO-1 and NQO1. These enzymes help to maintain intracellular redox balance and therefore protect cells from oxidative stress damage (18-22). The present study identified that SFN protected PC12 cells against the cytotoxicity of MPP+ and at the same time also restored the expression of Nrf2, HO-1 and NQO1 that was decreased by MPP+. Considering that these molecular signals are well-established cell protectors $(21,22)$, the present study hypothesized that activation of Nrf2,-HO-1 and NQO1 may account for the protective effects of SFN. The present study only examined HO-1 and NQO1 expression. However, the Nrf2/ARE pathway can induce the expression of a wide variety of downstream phase II detoxifying and antioxidant enzymes. In addition, HO-1 and NQO1, a number of other enzymes may also be activated, including GST, superoxide dismutase 3 and glucuronosyltransferase-1a6 (52). Further studies are required to elucidate the entire pathway for SFN protection. 

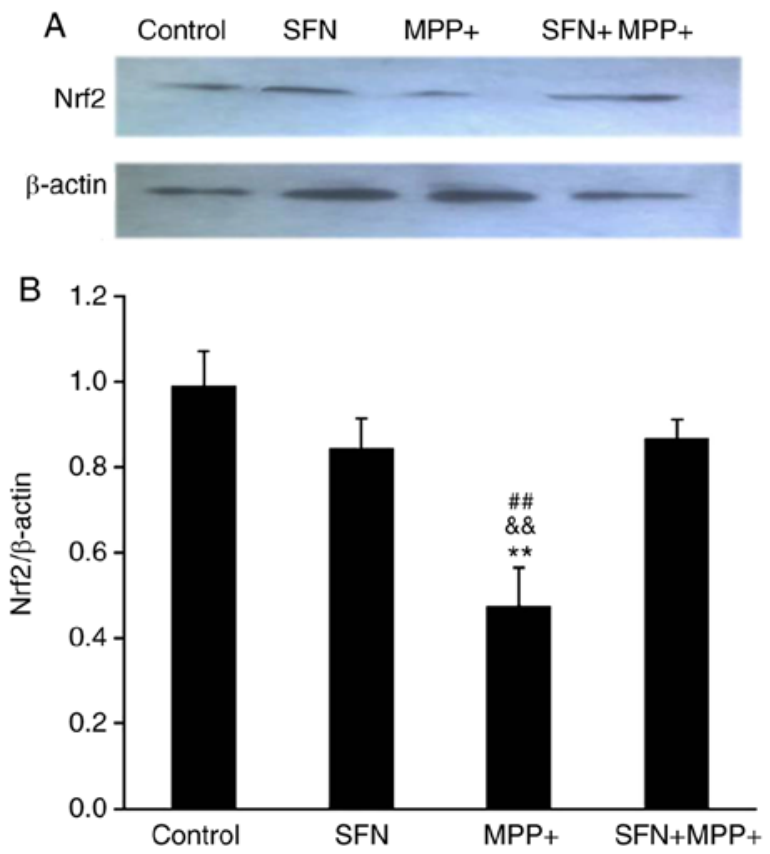

Figure 4. Nrf2 expression in PC12 cells was determined by western blot assay. (A) Representative bands of Nrf2 in PC12 cells treated with SFN, $\mathrm{MPP}+$, or $\mathrm{SFN}$ and MPP+ together. (B) Normalized Nrf2 expression in PC12 cells. ${ }^{* *} \mathrm{P}<0.01$ vs. the control group; ${ }^{\&}{ }^{\&} \mathrm{P}<0.01$ vs. the $\mathrm{SFN} ;{ }^{\# \#} \mathrm{P}<0.01$ vs. the SFN+MPP+ group. One-way analysis of variance was used to analyze the data. SFN, sulforaphane; MPP+, 1-methyl-4-phenyl pyridine ion; Nrf2, nuclear factor erythroid 2-related factor 2.
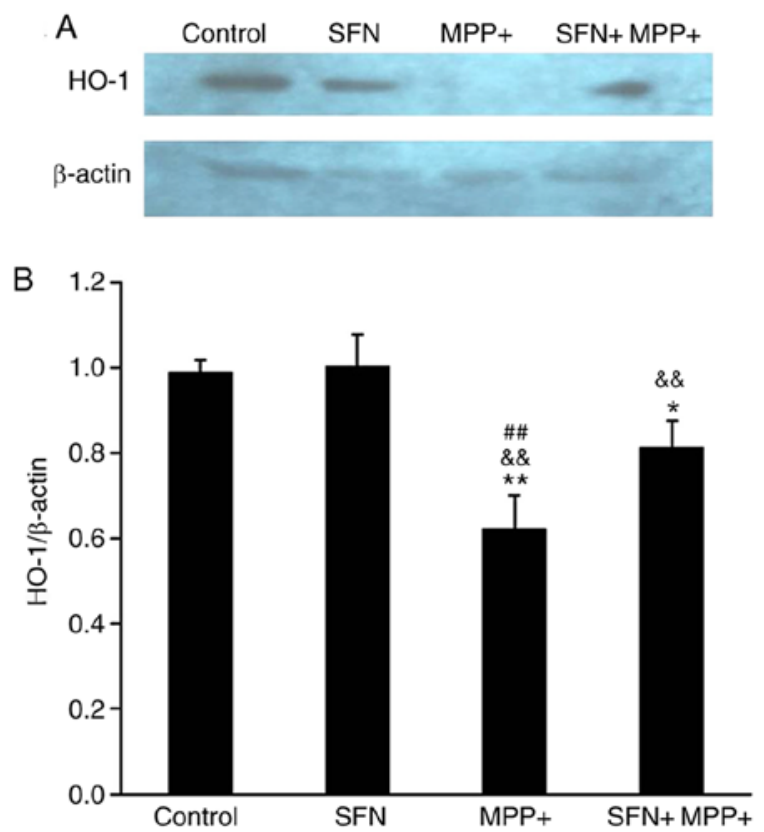

Figure 5. HO- 1 expression in the PC12 cells determined by western blot assay. (A) Representative bands of HO-1 in PC12 cells treated with SFN, $\mathrm{MPP}+$, or SFN and MPP+ together. (B) Normalized HO-1 expression in $\mathrm{PC} 12$ cells. ${ }^{*} \mathrm{P}<0.05$ vs. the control group; ${ }^{* *} \mathrm{P}<0.01$ vs. the control group; ${ }^{\&} \mathrm{P}<0.01$ vs. $\mathrm{SFN} ;{ }^{\# \#} \mathrm{P}<0.01$ vs. $\mathrm{SFN}+\mathrm{MPP}+$ group. One-way analysis of variance was used to analyze the data. SFN, sulforaphane; MPP+, 1-methyl-4-phenyl pyridine ion; HO-1, heme oxygenase 1.

Studies have demonstrated that SFN can regulate certain neurotransmitters and their receptors $(53,54)$. For example,
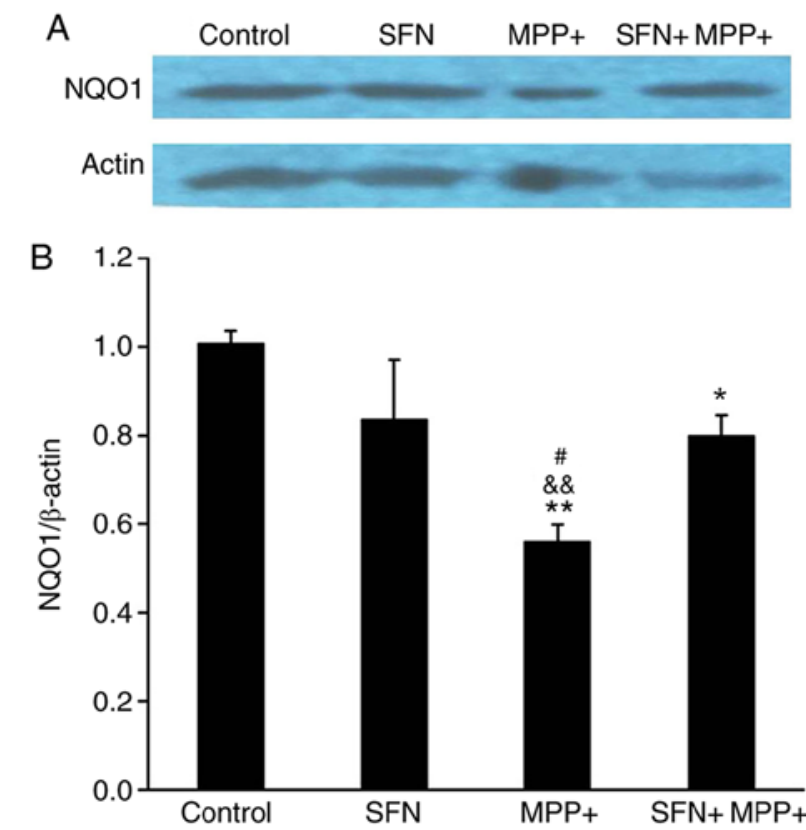

Figure 6. NQO1 expression in the PC12 cells determined by western blot assay. (A) Representative bands of NQO1 in PC12 cells treated with SFN, $\mathrm{MPP}+$, or SFN and MPP+. (B) Normalized NQO1 expression in PC12 cells. ${ }^{*} \mathrm{P}<0.05$ vs. the control group; ${ }^{* *} \mathrm{P}<0.01$ vs. the control group; ${ }^{\&} \& \mathrm{P}<0.01$ vs. $\mathrm{SFN}$; $\mathrm{P}<0.05$ vs. SFN+MPP+ group. One-way analysis of variance was used to analyze the data. SFN, sulforaphane; MPP+, 1-methyl-4-phenyl pyridine ion; NQO1, nicotinamide quinone oxidoreductase 1.

Mastrangelo et al (53) identified that SFN inhibited the secretion of serotonin and downregulated the expression of its receptors in human colorectal adenocarcinoma cells. While Lee et al (54) demonstrated that SFN increased acetylcholine production and its receptor expression in primary cortical neurons. Progressive degeneration of dopaminergic neurons in the substantia nigra is the main mechanism of PD. However, reductions in dopamine content and uptake indices have also been documented in PD $(55,56)$. The present study demonstrated that SFN prevented PC12 cell death induced by MPP+. In addition, it would be also interesting to determine whether SFN affects dopamine production or the expression of its receptors/transporters in dopaminergic neurons.

It should be noted that one limitation of the present study is that ROS production was not measured during the treatments with different compounds. Although several studies have demonstrated that ROS is a critical mediator in the MPP+-induced cell injury, the evaluation of ROS productions in this study would more definitively elucidate the interrelation between the Nrf2/ARE pathway and ROS.

In conclusion, SFN, a naturally occurring compound, protected PC12 cells from MPP+-induced damage and the protective effects are in part due to the activation of the Nrf2-ARE signaling pathway. The results imply that certain plant-derived supplements including SFN can assist in modifying various biochemical and physiological risk factors in neurodegenerative diseases like PD, particularly environmentally induced symptoms of PD. Further studies are needed to examine the efficacy of SFN on animal models and ultimately in patients with neurological diseases including PD. 


\section{Acknowledgements}

The authors sincerely thank Dr Meiling Joiner, Department of Physiology the University of Iowa, for her diligent proofreading of the manuscript.

\section{Funding}

The present study was supported by the National Natural Science Foundation of China (awarded to XPY and ZYC; grant nos. 81760221 and 81260211), National Science \& Technology Fundational Resource Investigation Program of China (awarded to XPY; grant no. 2018FY100900) and Youth Project of Education Department of Jiangxi Province (awarded to BB; grant no. 151007).

\section{Availability of data and materials}

All data generated or analyzed during this study are included in this published article.

\section{Authors' contributions}

BB, MQZ and XPY conceived and planned the experiments. BB, MQZ, ZYC, XBW, ZBX and JYC performed the experiments. BB, MQZ, ZYC, XBW, ZBX, JYC and XPY interpreted and analyzed the data. BB and XPY wrote the manuscript.

\section{Ethics approval and consent to participate}

Not applicable.

\section{Patient consent for publication}

Not applicable.

\section{Competing interests}

The authors declare that they have no competing interests.

\section{References}

1. Dauer W and Przedborski S: Parkinson's disease: Mechanisms and models. Neuron 39: 889-909, 2003.

2. Tolleson CM and Fang JY: Advances in the mechanisms of Parkinson's disease. Discov Med 15: 61-66, 2013.

3. Coyle JT and Puttfarcken P: Oxidative stress, glutamate, and neurodegenerative disorders. Science 262: 689-695, 1993.

4. Zhou C, Huang Y and Przedborski S: Oxidative stress in Parkinson's disease: A mechanism of pathogenic and therapeutic significance. Ann N Y Acad Sci 1147: 93-104, 2008.

5. Liu Z, Zhou T, Ziegler AC, Dimitrion P and Zuo L: Oxidative stress in neurodegenerative diseases: From molecular mechanisms to clinical applications. Oxid Med Cell Longev 2017: 2525967, 2017.

6. Lerin C, Rodgers JT, Kalume DE, Kim SH, Pandey A and Puigserver P: GCN5 acetyltransferase complex controls glucose metabolism through transcriptional repression of PGC-1alpha. Cell Metab 3: 429-438, 2006.

7. Jha N, Kumar MJ, Boonplueang R and Andersen JK: Glutathione decreases in dopaminergic PC12 cells interfere with the ubiquitin protein degradation pathway: Relevance for Parkinson's disease? J Neurochem 80: 555-561, 2002.

8. Wang JJ, Zhang T, Niu DB, Wang K, Li KR, Xue B and Wang XM: Doxycycline-regulated co-expression of GDNF and TH in PC12 cells. Neurosci Lett 401: 142-145, 2006.
9. Liu Y, Liu L, Ying XX, Wei WJ, Han C, Liu Y, Han $\mathrm{CH}$, Leng AJ, Ma JY and Liu J: Dried rehmannia root protects against glutamate-induced cytotoxity to PC12 cells through energy metabolism-related pathways. Neural Regen Res 12: 1338-1346, 2017.

10. Soane L, Li Dai W, Fiskum G and Bambrick LL: Sulforaphane protects immature hippocampal neurons against death caused by exposure to hemin or to oxygen and glucose deprivation. J Neurosci Res 88: 1355-1363, 2010.

11. Xu C, Huang MT, Shen G, Yuan X, Lin W, Khor TO, Conney $\mathrm{AH}$ and Kong AN: Inhibition of 7,12-dimethylbenz(a) anthracene-induced skin tumorigenesis in C57BL/6 mice by sulforaphane is mediated by nuclear factor E2-related factor 2. Cancer Res 66: 8293-8296, 2006.

12. Fisher ML, Ciavattone N, Grun D, Adhikary G and Eckert RL: Sulforaphane reduces $\mathrm{YAP} / \Delta \mathrm{Np} 63 \alpha$ signaling to reduce cancer stem cell survival and tumor formation. Oncotarget 8: 73407-73418, 2017

13. Kubo E, Chhunchha B, Singh P, Sasaki H and Singh DP. Sulforaphane reactivates cellular antioxidant defense by inducing Nrf2/ARE/Prdx6 activity during aging and oxidative stress. Sci Rep 7: 14130, 2017.

14. Thejass P and Kuttan G: Immunomodulatory activity of sulforaphane, a naturally occurring isothiocyanate from broccoli (Brassica oleracea). Phytomedicine 14: 538-545, 2007.

15. Greaney AJ, Maier NK, Leppla SH and Moayeri M: Sulforaphane inhibits multiple inflammasomes through an Nrf2-independent mechanism. J Leukoc Biol 99: 189-199, 2016.

16. Dwivedi S, Rajasekar N, Hanif K, Nath C and Shukla R Sulforaphane ameliorates okadaic acid-induced memory impairment in rats by activating the Nrf2/HO-1 antioxidant pathway. Mol Neurobiol 53: 5310-5323, 2016.

17. Jang $M$ and Cho IH: Sulforaphane ameliorates 3-nitropropionic acid-induced striatal toxicity by activating the keap1-Nrf2-ARE pathway and inhibiting the MAPKs and NF- $\kappa \mathrm{B}$ pathways. Mol Neurobiol 53: 2619-2635, 2016

18. Minelli A, Conte C, Cacciatore I, Cornacchia C and Pinnen F: Molecular mechanism underlying the cerebral effect of Gly-Pro-Glu tripeptide bound to L-dopa in a Parkinson's animal model. Amino Acids 43: 1359-1367, 2012.

19. Chen PC, Vargas MR, Pani AK, Smeyne RJ, Johnson DA, Kan YW and Johnson JA: Nrf2-mediated neuroprotection in the MPTP mouse model of Parkinson's disease: Critical role for the astrocyte. Proc Natl Acad Sci USA 106: 2933-2938, 2009 .

20. Yin XP, Chen ZY, Zhou J, Wu D and Bao B: Mechanisms underlying the perifocal neuroprotective effect of the Nrf2-ARE signaling pathway after intracranial hemorrhage. Drug Des Devel Ther 9: 5973-5986, 2015.

21. Yin XP, Wu D, Zhou J, Chen ZY, Bao B and Xie L: Heme oxygenase 1 plays role of neuron-protection by regulating Nrf2-ARE signaling post intracerebral hemorrhage. Int J Clin Exp Pathol 8: 10156-10163, 2015.

22. Chen G, Fang Q, Zhang J, Zhou D and Wang Z: Role of the Nrf2-ARE pathway in early brain injury after experimental subarachnoid hemorrhage. J Neurosci Res 89: 515-523, 2011.

23. Rostamian DelavarM,Baghi M, Safaeinejad Z,Kiani-Esfahani A, Ghaedi K and Nasr-Esfahani MH: Differential expression of miR-34a, miR-141, and miR-9 in MPP+-treated differentiated PC12 cells as a model of Parkinson's disease. Gene 662: 54-65, 2018.

24. Cheng W, Chen W, Wang $\mathrm{P}$ and Chu J: Asiatic acid protects differentiated PC12 cells from $\mathrm{A} \beta_{25-35}$-induced apoptosis and tau hyperphosphorylation via regulating PI3K/Akt/GSK-3 $\beta$ signaling. Life Sci 208: 96-101, 2018.

25. Yin $X$, Zhang $X$, Wang W, Chang L, Jiang $Y$ and Zhang $S$ : Perihematoma damage at different time points in experimental intracerebral hemorrhage. J Huazhong Univ Sci Technolog Med Sci 26: 59-62, 2006.

26. Yin M, Chen Z, Ouyang Y, Zhang H, Wan Z, Wang H, Wu W and Yin X: Thrombin-induced, TNFR-dependent miR-181c downregulation promotes MLL1 and NF- $\kappa \mathrm{B}$ target gene expression in human microglia. J Neuroinflammation 14: 132, 2017.

27. Kajimura Y, Aoki T, Kuramochi K, Kobayashi S, Sugawara F, Watanabe N and Arai T: Neoechinulin A protects PC12 cells against MPP+-induced cytotoxicity. J Antibiot (Tokyo) 61: 330-333, 2008

28. Lu XL, Lin YH, Wu Q, Su FJ, Ye CH, Shi L, He BX, Huang FW, Pei $\mathrm{Z}$ and Yao XL: Paeonolum protects against MPP(+)-induced neurotoxicity in zebrafish and PC12 cells. BMC Complement Altern Med 15: 137, 2015 
29. Houghton CA, Fassett RG and Coombes JS: Sulforaphane and other nutrigenomic Nrf2 activators: Can the clinician's expectation be matched by the reality? Oxid Med Cell Longev 2016 7857186, 2016

30. Calkins MJ, Johnson DA, Townsend JA, Vargas MR, Dowell JA, Williamson TP, Kraft AD, Lee JM, Li J and Johnson JA: The Nrf2/ARE pathway as a potential therapeutic target in neurodegenerative disease. Antioxid Redox Signal 11: 497-508, 2009.

31. Gilgun-Sherki Y, Rosenbaum Z, Melamed E and Offen D: Antioxidant therapy in acute central nervous system injury: Current state. Pharmacol Rev 54: 271-284, 2002.

32. Hartley A, Stone JM, Heron C, Cooper JM and Schapira AH: Complex I inhibitors induce dose-dependent apoptosis in PC12 cells: Relevance to Parkinson's disease. J Neurochem 63 : 1987-1990, 1994

33. Zhang L, Huang L, Li X, Liu C, Sun X, Wu L, Li T, Yang H and Chen J: Potential molecular mechanisms mediating the protective effects of tetrahydroxystilbene glucoside on $\mathrm{MPP}^{+}$-induced PC12 cell apoptosis. Mol Cell Biochem 436: 203-213, 2017.

34. Ye S, Koon HK, Fan W, Xu Y, Wei W, Xu C and Cai J: Effect of a traditional chinese herbal medicine formulation on cell survival and apoptosis of $\mathrm{MPP}^{+}$-treated MES 23.5 dopaminergic cells. Parkinsons Dis 2017: 4764212, 2017.

35. Zhang Z, Li C, Shang L, Zhang Y, Zou R, Zhan Y and Bi B Sulforaphane induces apoptosis and inhibits invasion in U251MG glioblastoma cells. Springerplus 5: 235, 2016.

36. Zuryń A, Litwiniec A, Safiejko-Mroczka B, KlimaszewskaWiśniewska A, Gagat M, Krajewski A, Gackowska L and Grzanka D: The effect of sulforaphane on the cell cycle, apoptosis and expression of cyclin D1 and p21 in the A549 non-small cell lung cancer cell line. Int J Oncol 48: 2521-2533, 2016.

37. Pledgie-Tracy A, Sobolewski MD and Davidson NE: Sulforaphane induces cell type-specific apoptosis in human breast cancer cell lines. Mol Cancer Ther 6: 1013-1021, 2007.

38. An YW, Jhang KA, Woo SY, Kang JL and Chong YH: Sulforaphane exerts its anti-inflammatory effect against amyloid- $\beta$ peptide via STAT- 1 dephosphorylation and activation of Nrf2/HO-1 cascade in human THP-1 macrophages. Neurobiol Aging 38: 1-10, 2016.

39. Pearson BL, Simon JM, McCoy ES, Salazar G, Fragola G and Zylka MJ: Identification of chemicals that mimic transcriptional changes associated with autism, brain aging and neurodegeneration. Nat Commun 7: 11173, 2016.

40. Chirumbolo S and Bjørklund G: Sulforaphane and 5-fluorouracil synergistically inducing autophagy in breast cancer: A possible role for the Nrf2-Keap1-ARE signaling? Food Chem Toxicol 2018.

41. Wang F, Wang W, Li J, Zhang J, Wang X and Wang M: Sulforaphane reverses gefitinib tolerance in human lung cancer cells via modulation of sonic hedgehog signaling. Oncol Lett 15 : 109-114, 2018

42. Ramirez CN, Li W, Zhang C, Wu R, Su S, Wang C, Gao L, Yin R and Kong AN: In vitro-in vivo dose response of ursolic acid, sulforaphane, PEITC, and curcumin in cancer prevention. AAPS J 20: 19, 2017.

43. Evans PC: The influence of sulforaphane on vascular health and its relevance to nutritional approaches to prevent cardiovascular disease. EPMA J 2: 9-14, 2011.

44. Nagata N, Xu L, Kohno S, Ushida Y, Aoki Y, Umeda R, Fuke N, Zhuge F, Ni Y, Nagashimada M, et al: Glucoraphanin ameliorates obesity and insulin resistance through adipose tissue browning and reduction of metabolic endotoxemia in mice. Diabetes 66 : 1222-1236, 2017
45. Brown RH, Reynolds C, Brooker A, Talalay P and Fahey JW: Sulforaphane improves the bronchoprotective response in asthmatics through Nrf2-mediated gene pathways. Respir Res 16: $106,2015$.

46. Xin Y, Bai Y, Jiang X, Zhou S, Wang Y, Wintergerst KA, Cui T, Ji H, Tan Y and Cai L: Sulforaphane prevents angiotensin II-induced cardiomyopathy by activation of Nrf2 via stimulating the Akt/GSK-3ß/Fyn pathway. Redox Biol 15: 405-417, 2018.

47. Stepniewski J, Pacholczak T, Skrzypczyk A, Ciesla M, Szade A, Szade K, Bidanel R, Langrzyk A, Grochowski R, Vandermeeren F, et al: Heme oxygenase-1 affects generation and spontaneous cardiac differentiation of induced pluripotent stem cells. IUBMB Life 70: 129-142, 2018.

48. Dinkova-Kostova AT, Fahey JW, Kostov RV and Kensler TW: KEAP1 and done? targeting the NRF2 pathway with sulforaphane. Trends Food Sci Technol 69: 257-269, 2017.

49. Izumi $Y$, Kataoka H, Inose Y, Akaike A, Koyama Y and Kume T: Neuroprotective effect of an Nrf2-ARE activator identified from a chemical library on dopaminergic neurons. Eur J Pharmacol 818: 470-479, 2018.

50. Cho JH, Kim YW and Keum YS: Sulforaphane suppresses LPS-induced or TPA-induced downregulation of PDCD4 in RAW 264.7 cells. Phytother Res 28: 1606-1611, 2014.

51. Ma Q: Role of nrf2 in oxidative stress and toxicity. Annu Rev Pharmacol Toxicol 53: 401-426, 2013.

52. Cho HY, Jedlicka AE, Reddy SP, Kensler TW, Yamamoto M, Zhang LY and Kleeberger SR: Role of NRF2 in protection against hyperoxic lung injury in mice. Am J Respir Cell Mol Biol 26: 175-182, 2002.

53. Mastrangelo L, Cassidy A, Mulholland F, Wang W and Bao Y: Serotonin receptors, novel targets of sulforaphane identified by proteomic analysis in Caco-2 cells. Cancer Res 68: 5487-5491, 2008.

54. Lee S, Kim J, Seo SG, Choi BR, Han JS, Lee KW and Kim J: Sulforaphane alleviates scopolamine-induced memory impairment in mice. Pharmacol Res 85: 23-32, 2014.

55. Chinaglia G, Alvarez FJ, Probst A and Palacios JM: Mesostriatal and mesolimbic dopamine uptake binding sites are reduced in Parkinson's disease and progressive supranuclear palsy: A quantitative autoradiographic study using [3H]mazindol. Neuroscience 49: 317-327, 1992.

56. Leenders KL, Salmon EP, Tyrrell P, Perani D, Brooks DJ, Sager H, Jones T, Marsden CD and Frackowiak RS: The nigrostriatal dopaminergic system assessed in vivo by positron emission tomography in healthy volunteer subjects and patients with Parkinson's disease. Arch Neurol 47: 1290-1298, 1990.

This work is licensed under a Creative Commons Attribution-NonCommercial-NoDerivatives 4.0 International (CC BY-NC-ND 4.0) License. 